\title{
"Há um mundo africano inteiro à nossa espera" Entrevista com Wilson Trajano Filho: Um profissional da alteridade
}

Por

Denise Pimenta Laura Moutinho Pedro Lopes

Universidade de São Paulo São Paulo, sp, Brasil

Imoutinho@usp.br pimenta@usp.br pedro.lopes@usp.br

Recentemente, ainda no ano de 2016, Wilson Trajano Filho tornou-se Professor Titular do Departamento de Antropologia Social da Universidade de Brasília (DAN-UnB), consagrando o reconhecimento de uma longa carreira dedicada à antropologia, em especial aos Estudos Africanos.

Trajano Filho vive atualmente entre Brasília e Berlim, exercendo as funções de docência e pesquisa tanto no Departamento de Antropologia da unB como no Max Planck Institute. Com uma posição já consolidada e reconhecida internacionalmente, Trajano Filho possui uma vida acadêmica agitada e cheia de vivacidade. Entre suas inúmeras atividades, abriu gentilmente uma brecha em sua agenda atribulada para nos conceder a entrevista a seguir.

Trajano Filho nos brindou com a narrativa de sua história acadêmica, que além de original (quantos antropólogos brasileiros foram formados nos quatro campos boasianos?) se mistura com o próprio campo da Antropologia da África. Ele nos mostra como os diferentes momentos de sua trajetória não seguiram planos previamente desenhados ou linhas simples. Os leitores poderão seguir com o autor um percurso que vai da música à antropologia e da antropologia às pesquisas em África. Sem dúvida alguma, estamos frente a um caminho instigante, que o conduziu à sua sólida carreira atual, especialmente dedicada a refletir sobre as representações de nação, o colonialismo português em África, a cultura popular e a crioulização.

Sendo talvez o primeiro brasileiro da recente antropologia realizada no Brasil a pesquisar em África, Trajano Filho nos ofereceu um relato sobre sua trajetória acadêmica, que passou pelos desafios e aprendizados de seu trabalho de campo na África do Oeste, principalmente na Cuiné-Bissau, desenvolvendo reflexões essenciais e provocativas sobre o ofício da antropologia e, especial- 
mente, sobre sua feitura no território africano. Convidando-nos, portanto, a pensar desde sua posição, seu panorama nos oferece uma perspectiva ampliada e densa sobre os caminhos da antropologia no Brasil, bem como os desafios em vista para uma antropologia contemporânea balizada em relações sul-sul. Como não poderia deixar de ser, a tela - ou partitura - que se compõe descreve um campo altamente politizado, reflexivo e sensível.

Dentre os inúmeros e interessantes assuntos abordados na entrevista, Trajano Filho nos convida a refletir a respeito da questão de gênero que atravessa e por vezes constitui os trabalhos de antropólogos e antropólogas que se dedicam aos Estudos Africanos e à antropologia em África, fazendo referência a importantes nomes femininos na área e na disciplina. Além disso, mostra que a dedicação de pesquisadores brasileiros - da área da antropologia - aos países africanos de colonização portuguesa não é necessariamente o caminho mais interessante, apesar de poder parecer o mais óbvio.

Assim, a entrevista concedida por Wilson Trajano Filho à Revista de Antropologia, é ela mesma uma experiência antropológica instigante, com anedotas, desvios e caminhos surpreendentes, estes mesmos que nos são tão familiares, e ao mesmo tempo tão estranhados, em nosso ofício.

\section{TRANSIÇÃO DA MÚSICA PARA A ANTROPOLOGIA}

- Com mais de 40 anos de jornada profissional e acadêmica, você descreve um percurso "da música à conversão à antropologia", termo usado por você para falar desta transição entre as áreas. Dentre estes 41 anos, 34 foram dedicados à antropologia e 23 à docência no Departamento de Antropologia da Universidade de Brasília. Resgatando Weber, poderíamos dizer que você seguiu o caminho da antropologia como vocação? Você poderia falar um pouco sobre como se deu esta jornada, em que momento a música como oficio perde espaço para a antropologia em sua trajetória acadêmica?

WT - Em mais de uma ocasião, eu escrevi que a história de meus vínculos com a antropologia é a dos meus desvínculos com a música. Eu me formei em música, na habilitação em Composição e Regência, em 1979. Para ser preciso, devo dizer que a composição sempre me interessou mais que a regência. Nunca tive a vaidade que ainda hoje me soa superficial dos regentes. Costo de dizer que me faltava um talento natural para esse ofício. Meus cabelos são crespos - de anjinho barroco, gosto de pensar-, e não fazem grande efeito no descabelar dos regentes românticos no auge de suas performances. Como compositor, acho que tinha algum talento. Minhas peças, das quais hoje só tenho as partituras, soavam bem, eram expressivas, mas hiper contemporâneas, sem concessões à tonalidade nem ao ouvir fácil. Eu vivia 
fascinado com os sons novos e inesperados, produzidos acusticamente. Em vez do recurso aos sintetizadores (aqui a proximidade é com Boulez, Stockhausen e Pousseur, e não com o rock progressivo dos anos 70) ou aos sons naturais transformados por filtros de várias espécies da chamada música concreta, eu gostava de me aventurar na produção de novidades sonoras com os instrumentos tradicionais. Percutir as cordas com a madeira do arco e não com a crina, passar o arco no estandarte dos violoncelos e contrabaixos ou nas cordas, mas entre o cavalete e o estandarte, produzir acordes com os instrumentos de sopros... Esses eram alguns dos sons que faziam parte do repertório com o qual trabalhava. Além disto, eu também tinha um gosto pelas formas puras: queria esticá-las, esgarçá-las e subvertê-las até que as transformasse totalmente, sem deixar vestígios do que originalmente eram.

Eu seguia bem na incipiente carreira de compositor, tinha minhas obras executadas e a admiração de meus professores e colegas. Acho que foi como uma promessa que fui aprovado num concurso para professor no Departamento de Artes e Comunicação da UFPB, no final de 1979. Saí da Escola de Música de Brasília, onde lecionava quase 30 horas de aula por semana, a maioria delas de "teoria e solfejo", e fui para João Pessoa sonhando em ter tempo para compor. Não consegui e acho que não vale a pena aqui especular sobre as razões desse fracasso. Faço isto em meu Memorial para Professor Titular. Buscando uma saída para o deserto musical e existencial que vivia em João Pessoa, voltei para Brasília e fui fazer o mestrado em antropologia.

Por que a antropologia? Costo de dizer e de pensar que foi por amor. A minha companheira da vida tinha feito uma graduação em antropologia e eu era tão apaixonado que além de achá-la linda, via beleza e magia também em tudo o que ela fazia, incluindo a antropologia. Os psicólogos certamente têm um nome pra isto, mas a palavra me foge agora. Em todo caso, se há algo de vocação no sentido weberiano, isto veio com o passar do tempo. Na oposição que Weber faz entre profissão e vocação, parece-me não haver dúvida que minha inserção tinha mais da última que da primeira, mas vamos e venhamos que não há nada de espantoso nisto. Afinal, encarar a antropologia como profissão seria naquela época uma escolha um tanto atabalhoada, até para quem vinha da música. Por outro lado, Weber faz uma distinção entre ciência e arte, e minha formação na antropologia, enquanto processo, não tinha o mesmo desenho que ele propõe para uma carreira científica. Entrei na antropologia pelos sentidos e pelo afeto, me socializei ali pelas mesmas vias. Foi só muito lentamente que me tornei antropólogo e só consegui essa façanha me desvinculando lentamente da prática musical. Comecei o mestrado em 1981, fui para os Estados Unidos em 1984 fazer meu doutorado e só deixei de fazer música no início dos anos 90, depois de um 
esforço mal sucedido na composição de uma trilha sonora para um filme cuja produção era muito confusa. Fiz o meu trabalho, fui bem pago para tal. Há ali alguns trechos de grande beleza sonora, mas o resultado final é deplorável. Depois disso, eu resolvi que nunca mais me aventuraria em águas nas quais eu já não mais nadava, onde me faltava o métier.

\section{MESTRADO E DOUTORADO EM ANTROPOLOGIA}

-Sua trajetória acadêmica pela antropologia começa com um mestrado pelo dan-unb intitulado "Músicos e Música no meio da Travessia" (Trajano Filho, 1984), sob grande influência das leituras de Erving Coffman. Mesmo o tema estando atrelado à música, parece que não poderíamos situar o trabalho na etnomusicologia. Assim, porque a não escolha desta área dentro da antropologia?

WT - Vocês estão absolutamente corretas. Minha dissertação de mestrado é tudo menos um trabalho de etnomusicologia. Influenciado, por um lado, por Coffman e por leituras fragmentadas (isto é, sem a sistematização dada por um mestre ou um guia) dos sociólogos da Escola de Chicago e, por outro lado, por antropólogos fascinados com a eficácia dos rituais, meu trabalho é sobre a carreira dos músicos profissionais, como ela é construída e reproduzida. Para fazer isto, dei atenção especial aos ritos musicais, como os concertos de música clássica e os shows de música popular. Acredito que essas ocasiões, e, sobretudo, os ensaios que as precedem, fazem o músico. Uma orquestra sinfônica existe como um nome e como um ato (de experiência). Este último é o complexo conjunto de ações que ocorre entre o primeiro ensaio e o concerto, envolvendo centenas de pessoas, cada uma com sua carreira profissional e moral. Neste ato, temos a (re)criação e a afirmação das carreiras musicais e das hierarquias próprias do mundo da música.

Por que não fazer pesquisa etnomusicológica? Que tal uma resposta goffmaniana? Eu queria fugir do estigma. Numa comunidade tão pequena como a dos antropólogos naquela época, vir da música e fazer uma antropologia da música me conferiria uma marca que não me apetecia ter-ou assim eu pensava então. Hoje vejo que isto é uma bobagem. Meu colega de Departamento, José Jorge de Carvalho, e meu querido amigo da uFsc, Rafael Bastos de Menezes, tiveram essa mesma trajetória e não são portadores de nenhuma marca estigmatizante. Pelo contrário, são altamente respeitados e seus trabalhos são muito bem reconhecidos.

No entanto, por mais verdadeiro que tenha sido o esforço de fugir de um eventual estigma, essa não é a reposta completa à pergunta que vocês me fizeram. Não quis me envolver com a etnomusicologia porque não via nela uma grande produtividade, pelo menos na sua forma mais ortodoxa. Acho 
que ela usa canhões para matar pequenos passarinhos: o instrumental da análise musicológica, desenvolvido para lidar com a produção musical da tradição ocidental, usado para tratar dos mundos sonoros de outras sociedades. Em suas feições tradicionais, esse uso acaba por exotizar e simplificar comparativamente o que não é ocidental. Além disto, o uso da notação musical ocidental sempre teve o potencial de gerar mistificações que abomino. A antropologia é cheia disto: no parentesco, nos esforços dos anos 50 e 60 de se construir uma antropologia econômica formalista, no namoro dos transacionalistas com a teoria dos jogos, em certas áreas da antropologia cognitiva. Essas mistificações, que envolvem uso de um jargão, notação ou um registro comunicativo esotérico, de acesso somente a uns poucos escolhidos, quase sempre retiram a dimensão a ser analisada do mundo da vida em que ela está inserida, causando perdas de sentido irreparáveis.

Há muita etnomusicologia que escapa dessas armadilhas. Os colegas que aqui citei são exemplos disto, mas, de modo geral, continuo achando pouco produtiva analiticamente e nada imaginativa a maioria dos trabalhos nessa área. Por isto fugi dela o quanto pude.

\section{- Como você fez a migração do tema do mestrado - relativo à música - para se voltar} para os estudos africanos no doutorado?

WT - Originalmente eu não fui aos estudos africanos. Tudo que queria era compreender os processos de construção nacional nos países recém-saídos da experiência colonial. Mas deixe-me ir com mais vagar sobre isto.

Desde que organizei a coletânea chamada O Campo da Antropologia no Brasil (Trajano Filho e Ribeiro, 2004) tenho consciência de que há na antropologia brasileira uma grande dominância dos temas nacionais. Ela tem quase sempre o Brasil como ponto de chegada. Essa era uma outra coisa da qual eu queria me afastar quando fui fazer meu doutoramento. Se no mestrado eu havia estudado o meu grupo (os músicos profissionais), no doutorado eu queria me afastar o máximo possível da pesquisa em casa. Eu queria ter a experiência de me encontrar com uma alteridade radical, cruzando fronteiras civilizatórias. Não me bastava ir para fora do Brasil e ficar no universo europeu ou (latino)americano, dentro da mesma vertente civilizatória. No entanto, naquela altura eu não atinei para o fato de que não bastava uma longa viagem, um deslocamento espacial de grandes dimensões. No fundo, eu não percebi que mesmo fazendo pesquisa fora de casa, o tema de meu projeto estava implicitamente atrelado a uma preocupação muito típica da antropologia brasileira: o estudo dos processos de construção nacional. Mesmo querendo ir para longe, de alguma forma o Brasil era meu ponto de chegada. 
Um país africano recém-saído da experiência colonial parecia ser a melhor forma de cruzar as fronteiras civilizatórias. Dada a ênfase que o Departamento da University of Pennsylvania dava para a formação etnográfica e nos estudos de área, percebi que mesmo sem ter até então uma formação sistemática em etnologia africana, a África era o continente que um antropólogo de minha geração melhor conhecia por causa da leitura obrigatória dos clássicos africanistas. Em minha formação brasileira já tinha lido Evans-Pritchard, Radcliffe-Brown, Fortes, Cluckman, Turner, Mary Douglas, Epstein, Van Velsen, Clyde Mitchell, Paul Bohanann e outros tantos que fizeram pesquisa em África. Daí decidi fazer os seminários sobre temas africanos. Fiz cursos sobre organização social, religião, simbolismo, cultura política e história da África. E quanto mais eu aprofundava o meu conhecimento da literatura africanista, menos acentuada ficava a questão da construção nacional e mais interessante me parecia estudar a sociedade crioula da Guiné-Bissau. No Memorial para Professor Titular eu descrevo esse processo com mais pormenor. Por agora, o que quero salientar é que no início fui à Guiné estudar a nação e, com o tempo, passei a buscar compreender os processos de formação e reprodução da sociedade crioula do país. Então, a nação passou a ser apenas uma forma histórica, dentre muitas, do projeto crioulo para si mesmo.

-Seu doutorado foi na Universidade da Pensilvânia, nos Estados Unidos. Esta formação em antropologia por lá, nos anos de 1980, foi muito diferente da que acontecia no Brasil em termos de ensino, feitura da teoria e prática de campo?

WT - Isto dá pano pra manga. De certo modo eu tive uma dificuldade inicial de adaptação quando fui para a Filadélfia. Em primeiro lugar, porque o programa de lá era do tipo "quatro campos", implicando uma formação em linguística, arqueologia e antropologia biológica, além da antropologia social/cultural. Em segundo lugar, até eu tomar tento da situação, digamos nos primeiros quatro meses (um semestre letivo), eu achava que o nível da discussão e a quantidade e qualidade dos textos a serem lidos nas disciplinas dos chamados core courses (oito disciplinas cujos conteúdos seriam objetos da série de provas eliminatórias, chamada comprehensive, ao final do primeiro ano) era muito diferente do que eu estava acostumado no meu mestrado brasileiro. A discussão nas disciplinas da antropologia cultural me parecia ser um tanto superficial, meio arroz-com-feijão. Já as da arqueologia e antropologia biológica me eram muito difíceis, com uma bibliografia enorme e desconhecida, lidando com problemas que para mim faziam pouco sentido e fusando métodos herméticos demais para minha compreensão. Tafonomia, cladogênese e anagênese, radiação adaptativa, 
arqueologia processual e dezenas de outras palavras e expressões esotéricas tiveram de ser rapidamente incorporadas ao meu vocabulário (para piorar as coisas, em inglês). Além disso, éramos submetidos duas vezes por mês a testes práticos e rápidos de reconhecimento de ossos humanos, de hominídeos e de outros primatas (na verdade, fragmentos de ossos). Ao término do primeiro semestre descobri que o nível de compreensão demandada nesses cursos era muito abaixo do que eu originalmente imaginava e tive notas excelentes nessas matérias. Compreendi também a razão dos cursos da antropologia cultural ficarem aquém de minha expectativa: a maioria de meus colegas americanos entrava diretamente para o doutorado, vindos de uma graduação no padrão liberal arts education, na qual pouco se enfatizava uma formação profissional. Então, ao iniciar o meu segundo semestre, senti-me à vontade para não me matricular nas disciplinas da antropologia cultural que faziam parte dos core courses. Em lugar delas, me inscrevi nos seminários temáticos, frequentados pelos estudantes que já tinham passado pelo crivo do comprehensive.

De início, não gostei nada de me envolver com ossos e ferramentas feitas de lascas de pedra, mas aos poucos cresceu o encanto com a imaginação "à grande" dos arqueólogos e paleoantropólogos, que reconstroem grandes processos com pequenos fragmentos de dados. E mais: meu contato com esses campos da antropologia deu-me uma dimensão da experiência humana que eu não tinha com minha formação brasileira. De um modo muito prosaico, posso dizer que fazendo esses cursos eu perdi o medo da palavra evolução, que para mim deixou de ser uma ofensa-que por aqui dirigimos aos colegas de quem não gostamos. Por falar nisto, lembro-me bem de que numa das primeiras vezes que ofereci a disciplina Antropologia da África no PPCAS de Brasília, uma aluna foi muito crítica dos textos que programei para a primeira unidade, sobre o povoamento do continente africano. Ela detestou o tom evolucionista dos textos sobre a evolução humana. Tenho pra mim que ela preferia um criacionismo disfarçado de hermenêutica.

Outra diferença digna de nota é que a formação no Brasil enfatizava uma abordagem do social. Diferentemente de hoje, em que parece ter crescido uma difusa influência da antropologia cultural norte-americana, quando fiz o meu mestrado a ênfase era claramente no social e a grande fonte de inspiração era a antropologia britânica, com algumas pitadas do estruturalismo francês (pelo menos para quem não fazia etnologia indígena). Líamos Geertz, Sahlins, alguma coisa da ethnoscience, mas tudo isto era um mero suplemento aos textos sobre sistemas, estruturas e processos dos autores ingleses. Em meus quase três anos de residência na Universidade da Pensilvânia (onde cursei 12 matérias, além das 8 que foram aproveitadas de meu 
mestrado brasileiro) tive que, de alguma forma, lidar de modo produtivo com o etéreo conceito de cultura, tão caro aos colegas norte-americanos, dando assim alguma alma às frias estruturas e processos sociais. A síntese que alcancei entre sociedade e cultura parece-me dever muito ao que aprendi nos cursos e seminários que frequentei que relacionavam língua e cultura. Especial menção eu faço aos cursos Culture, Language and Society e Ethnography of Speaking dirigidos, respectivamente por Ward Coodenough e Dell Hymes.

Olhando retrospectivamente, passei a ver a cultura como uma rede de significados menos etérea que a perspectiva oferecida pela antropologia interpretativa, porque nesses cursos formativos aprendi a tratar de modo sistemático (alguns diriam rígido, outros, técnico, outros ainda, metódico) com as unidades de significação. Além disto, aprendi também a dar uma atenção especial à dimensão pragmática dos significados. Mas, apesar de tudo isto, ainda me vejo como um antropólogo social, mais interessado em processos sociais de longo prazo, em especial nas formas que tomam, que em cultura. Eu estudo processos de crioulização em sociedades crioulas e pouco falo de crioulização cultural, como é muito comum nesse campo.

Até agora refleti sobre as diferenças que se referem ao processo de formação. Agora gostaria de pensar um pouco, pela ordem, sobre duas outras diferenças: as práticas de campo e sobre o lugar da teoria.

Os mestrados feitos no início dos anos 80 no Brasil eram mais longos, com mais cursos a fazer e a possibilidade de uma pesquisa de campo pequena, mas efetiva. A minha, feita entre músicos profissionais no Rio de Janeiro, teve a duração de cinco meses. De modo geral, o trabalho de campo para o doutorado era um pouco mais longo, ma non tropo. Como naquela época as pesquisas doutorais quase sempre eram feitas no próprio país, não se punha a necessidade de aprender uma nova língua e a pesquisa era muitas vezes feita em várias etapas. Esta era uma prática impensável nos meus anos de doutorado americano. Passar, no mínimo, um ano em campo, aprender a língua local e ter uma imersão plena na vida da sociedade que estudamos eram os requisitos mínimos exigidos para se escrever uma tese doutoral. Eu cumpri o que de mim era esperado. Fui para Guiné-Bissau em novembro de 1987 e retornei ao Brasil já sem financiamento em setembro de 1988. Em quase 11 meses de pesquisa aprendi razoavelmente o crioulo guineense. Algum tempo depois, longo demais para os padrões americanos, retornei para uma segunda temporada de cinco meses, perfazendo mais de 15 meses de pesquisa.

As coisas aqui estão mudando a este respeito. Nossos doutorandos estão ficando mais tempo em campo. Meus orientandos no PPCAs de Brasília que 
fazem pesquisa em África raramente ficam menos de um ano em campo e todos aprendem com algum grau de proficiência as línguas locais. Acho que essa mudança é reflexo de uma tendência que vem se consolidando entre nós de fazer pesquisa fora do Brasil. Mas, se comparada às práticas habituais dos doutorandos norte-americanos, ainda ficamos pouco tempo em campo.

Por fim, um dedo de pensamento sobre o lugar da teoria. Tenho uma perspectiva um tanto ácida sobre isto, e na contramão da opinião de muita gente. De cara, devo dizer que meu modo de entender essa questão reflete a minha elevada autoestima.

Quando saí daqui para fazer o doutorado, fui acreditando numa espécie de divisão intelectual do trabal ho que hierarquiza teoria e produção de dados ou teoria e descrição. Ambicionava, portanto, fazer teoria, posicionando-me consequentemente no topo da estrutura que estratifica o trabaIho antropológico. Pra falar a verdade, acho que eu (e um bocado de meus colegas de então) era meio boboca: um tonto pretencioso nos melhores dias, um besta arrogante, nos piores.

Pois bem, nos Estados Unidos, vivendo numa comunidade antropológica muito mais diversificada (tinha colegas ingleses, franceses, da Nova Zelândia, do Canadá, de Trinidad, do México, da Índia, além dos americanos), notei que ninguém levava muito a sério essa divisão do trabalho. Meus colegas de lá queriam simplesmente compreender o mundo que estudavam da meIhor maneira possível e teoria não era mais que uma grade conceitual com a qual processamos as nossas observações. Sem boas observações não havia teoria no mundo que desse jeito ou que tivesse vida longa. Deste modo, fui aprendendo gradualmente que era uma grande bobagem a obsessão que levara na bagagem acerca do lugar da teoria. Isto é especialmente mais verdadeiro quando pensamos na tradição antropológica e na prática etnográfica em que descrição e teoria se misturam e se fertilizam mutuamente.

Não quero com isto diminuir o lugar e a importância da teoria na antropologia nem fazer loas à descrição microscópica (frequentemente verborrágica e vazia). Quero, isto sim, evitar a atitude de intelectual do interior que preza a erudição vazia, as citações e referências cruzadas a tudo que está na moda, desprezando o trabalho braçal, chato e cansativo de observar o cotidiano, registrar casos empíricos, averiguar e checar informações que nos são passadas por nossos interlocutores. Acho muito importante insistir sobre esse ponto, pois tenho percebido de modo recorrente que a suposta divisão do trabalho que hierarquiza teoria e descrição etnográfica corresponderia a uma divisão do trabalho entre antropólogos do norte e do sul global. Normalmente posta em tom de crítica e denúncia, essa perspectiva é muito comum nos países do sul e ganha apoio entre aqueles que, no norte, não estão 
bem posicionados nas escalas locais de prestígio intelectual.

Acho que essa perspectiva é problemática quando ela impele, como tenho visto com tristeza, jovens e talentosos pesquisadores a dispenderem seus recursos intelectuais (sempre e em todo lugar limitados e escassos) num esforço vão de pura teorização em detrimento da observação acurada, do registro minucioso dos acontecimentos e da crítica metodológica às evidências obtidas. O resultado de tudo isto com frequência é a erudição vazia, a imitação pura e dura (desprovida de criatividade e invenção) a repetição do jargão, a ausência de bons dados etnográficos e um sentimento dolorido, mas injustificado de vitimização. E isto é tão mais agudo agora que as fronteiras entre norte e sul, entre centro e periferia, estão se desvanecendo. Acho que retornaremos a isto ainda nesta conversa.

\section{TEMA DA PESQUISA DE DOUTORADO}

\section{- Poderia nos falar um pouco como surge a ideia de estudar nação em África e, mais} especificamente, na Guiné-Bissau? O seu artigo "Rumores: uma narrativa da nação" (Trajano Filho, 1993) figura, inclusive, entre os mais utilizados nos cursos de pós-graduação.

WT - De fato, trata-se de um trabalho que tem causado um certo impacto, tendo um papel maior que eu esperava na formação de nossos mestrandos e doutorandos. Curiosamente, é um texto que só foi "publicado" na nossa defunta e saudosa Série Antropologia, há mais de 20 anos. Digo defunta, não porque morreu, mas porque está relegada por nós mesmos a um limbo embaraçador. Nos tempos do Qualis, não ter ISSN, não ter regularidade, apesar da imensa agilidade, é um pecado terrível: não é uma publicação.

Pouco antes, eu sugeri a vocês que levei comigo para a Guiné a temática da nação, que tanto que nos obceca. Entendo que a novidade de meu trabalho (deste ao qual vocês se referem e de toda a minha tese de doutorado) foi tentar alcançar os projetos para a nação veiculados pelos rumores e não formulados nos livros, panfletos, discursos e documentos oficiais. A nação dos rumores é não oficial, é construída de baixo para cima e compete plenamente com a nação prevista e permitida pelo Estado.

De onde surgiu isto? Como vou elaborar mais adiante, da impossibilidade de pôr em prática o meu ingênuo projeto de olhar a construção nacional a partir dos aparelhos do Estado voltados para a educação. Veio de minha capacidade de improvisar, de me virar e de estar com os ouvidos abertos e atentos quando ia me socializar com os guineenses ao redor de uns coposseja de cerveja, aguardente ou de vinho (de uva, de caju ou de palma) - e um bom bafatoriu (petiscos). 
-Sobre seu tema de pesquisa, a África portuguesa, em seu Memorial para atingiro grau de Professor Titular, você diz que "a África portuguesa enganosamente pareceu uma escolha natural". Por que enganosamente?

WT -Eu, Omar Ribeiro Thomaz, Juliana Braz Dias e Kelly Cristiane Silva (2008) publicamos um trabalho na revista da ABA, a Vibrant, sobre o trabalho dos antropólogos brasileiros em África. Nesse texto, acho que concordamos que é enganosa a ideia de que a África de expressão oficial portuguesa é uma escolha natural para a aventura antropológica brasileira em África. A tão propalada verdade de que a língua portuguesa seria um elemento facilitador não passa de uma vontade mal disfarçada e não cumprida. Na Cuiné-Bissau, muito pouca gente fala o português e aqueles que o falam, o fazem num registro tão diferente do nosso que beira a ininteligibilidade. Em vários lugares, o falar português ainda é sinônimo de subordinação e lugar para memórias de violência. Portanto, mais afasta do que aproxima. Equivocada também é a ideia de que a comparação entre Cabo Verde, Guiné-Bissau, São Tomé, Angola e Moçambique é mais gramatical pelo fato de terem sido colônias de um mesmo império, o que as tornariam mais assemelhadas. Hoje não tenho dúvidas de que, se quero entender as dinâmicas da vida social na Guiné-Bissau, é melhor olhar para o que acontece no Senegal, na Guiné Conacri, na Serra Leoa e na Gâmbia. As ilhas de Cabo Verde estão um pouco mais longe, apesar de muito presentes no imaginário local. Angola, São Tomé e Moçambique são lugares tão ou mais distantes que o Brasil ou a França.

Além disto, eu temo que a naturalidade com que todo um grupo de antropólogos brasileiros se dirigiu para as antigas colônias portuguesas, como se fosse a coisa certa a fazer, talvez esconda veleidades imperiais a nos rondar. Não consigo deixar de pensar em Chico Buarque e seu fado tropical. Eita pensamento feio, esse! Mas nem de todo sem fundamento.

Longe de propor uma interdição à pesquisa na "África portuguesa". Trata-se simplesmente de um chamado para fazer a aventura antropológica em outros lugares. Fico feliz de ver que Laura [Moutinho] foi à África do Sul e Denise [Pimenta] vai à Serra Leoa. Uma antiga aluna e atual colega, Juliana Braz Dias, começou por Cabo Verde, mas depois também foi à África do Sul. Outro antigo orientando, Josué Castro, agora na Unicamp, fez uma longa pesquisa na Namíbia. Minha colega, Andrea de Souza Lobo, também começou em Cabo Verde e atualmente está se preparando para expandir sua pesquisa para o Senegal. Há um mundo africano inteiro à nossa espera. 


\section{TRABALHO DE CAMPO EM ÁFRICA}

- Você foi um dos primeiros brasileiros - talvez o primeiro - a se dedicar à empreitada de um trabalho de campo em África na área da antropologia. Poderia nos falar um pouco da sua primeira experiência em campo, sobre suas expectativas e a realidade encontrada?

WT - Minha chegada a Bissau em novembro de 1987, sem nenhum contato anterior com gente do país, retrata bem o meu jeito atabalhoado de fazer pesquisa, de um lado, e a minha coragem ou irresponsabilidade, de outro. Eu tinha uma verba mínima (cerca de 4.000 dólares) para passar cerca de um ano em campo, graças ao apoio da Fundação Ford (pelo incentivo do Peter Fry), dos fundos de auxílio à pesquisa da U. Penn e do que consegui economizar da bolsa do cNPq.

Minha proposta de investigação, esquemático que só, mencionava analisar os projetos para a nação veiculados pelo Estado guineense através do seu aparato escolar. A ideia geral era estudar os manuais de geografia e história da Cuiné usados nas escolas, averiguar os embates envolvidos em sua construção e sua recepção pelos estudantes em pontos diferentes do país. Não tardou muito para eu descobrir que o sistema escolar estava em colapso, os professores, sem receber seus míseros salários há mais de um ano, estavam em greve por um tempo semelhante, os manuais de história e geografia eram literalmente inexistentes e as poucas escolas particulares e confessionais ensinavam a história e a geografia da Europa (basicamente de Portugal e da França).

Tive que improvisar uma saída e achar uma temática alternativa para a pesquisa. Foi quando me deparei com a centralidade dos rumores nos centros urbanos do país, nas rodas de conversa nos poucos e decadentes bares e cafés de uma Bissau que ficava sem energia elétrica por meses a fio, nas sombras das mangueiras nos bairros periféricos e nos batanbas (pontos de encontro e conversa) das aldeias. Foi ouvindo esses rumores que descobri que muitos deles tematizavam direta ou indiretamente a nação: narravam acontecimentos vividos pela gente poderosa do país, especulavam sobre a fonte de seu poder, comentavam sobre as práticas místicas de estrangeiros misteriosos (africanos e europeus) e sobre como elas afetavam os guineenses, em geral as crianças. Interessado neste material fugidio e inusitado, percebi que eles expressavam projetos para a comunidade (a nação) formulados pelos estratos mais baixos da população. Passei a tratá-los como a nação vista de baixo, em competição com os projetos nacionais de natureza institucional (formulados pelo Estado, agências de cooperação internacional e, mais tarde, pelas nascentes oncs que passaram a infestar o país). 


\section{ORIENTAÇÃO E GÊNERO}

-Dentre várias orientações como professor, você formou duas professoras que hoje estão na unв com pesquisas em África. No entanto, ainda assim, a quantidade de mulheres estudando a região se mostra pequena, tanto no Brasil como em outros países. Você poderia refletir sobre este panorama, pois não nos parece que seja apenas uma falta de interesse pelo tema.

WT -É difícil falar sobre isto sem ter acesso a dados quantitativos. Tudo que vou dizer é muito intuitivo e se baseia na minha vivência, que é naturalmente estreita e limitada. Num cálculo grosseiro, estimo que haja atualmente cerca de 30 pesquisadores doutores vinculados aos programas de pós-graduação em antropologia fazendo pesquisa no continente africano, e um número ainda maior de gente fazendo o seu treinamento doutoral (estou deixando de lado os colegas, homens e mulheres, das áreas vizinhas à nossa como a história, a sociologia, a literatura e geografia). No primeiro grupo, conheço pessoalmente onze mulheres. Certamente há outras que não conheço. Em todo caso, é um pouco menos da metade daqueles que estão fazendo pesquisa em África. Isto, numa disciplina em que as mulheres são a maioria. No segundo grupo, minha estimativa está muito mais para um chute, mas posso dizer que tenho contato pessoal com pelo menos cinco pesquisadoras mulheres fazendo suas teses doutorais sobre aquela parte do mundo.

Vocês supõem que as mulheres são uma minoria na comunidade de antropólogos com interesse em África. E, cruelmente, me perguntam sobre as possíveis razões. Pode bem ser que as antropólogas interessadas no continente africano sejam em bem menor número do que os homens, mas quantidade certamente não é sinônimo de visibilidade. Na história da antropologia, há um significativo número de antropólogas com elevada visibilidade. No período clássico se destacam Audrey Richards, Monica Wilson, Germaine Dieterlen, Denise Paulme, Laura Bohannan, Sally Falk Moore, Mary Douglas e Hortense Powdermaker, para citar algumas. Mais recentemente, o número delas cresceu e certamente rivaliza com o dos homens. Posso dizer a vocês que nos países em que tenho experiência de pesquisa, há tantas ou mais mulheres fazendo pesquisa que homens.

Em todo caso, vou contar uma anedota que de alguma maneira me envolve e a partir daí especular sobre possíveis razões de a África eventualmente ser ou ter sido um lugar difícil para as mulheres antropólogas. Alguns anos atrás eu tive uma estudante de mestrado que eu queria que fosse para a Gâmbia, estudar um grupo crioulo dali pouco conhecido na literatura. De início, ela se mostrou interessada, mas quando chegou a hora do "vamos ver", ela desistiu. Eu estava fora do país, e acho que isto facilitou a sua desistência. 
Tudo que ela teve de fazer foi escrever um e-mail para mim dizendo que descobrira que o Presidente do país dizia ter o poder de curar pessoas com AIDS e isto, para ela, era moralmente inadmissível. Portanto, ela procuraria outro tema, em outro lugar e, como ficou implícito, outro(a) orientador(a). Ela assim o fez e concluiu o seu mestrado sobre um assunto ligado a gênero e cultura popular num outro país africano. Atualmente, está engajada em seu projeto doutoral, também voltado para África.

A conclusão dessa história nos conta que a pesquisa em África é claramente possível para as mulheres. Porém, o nosso olhar (o do Ocidente educado) para a África cristalizou alguns vieses que talvez tornem, de partida, a decisão de ali fazer pesquisa mais difícil para as mulheres. São vieses associados a uma encruzilhada terrível em que se misturam política e gênero: gerontocracia e autoritarismo, de um lado, e machismo e patriarcalismo, de outro. A ver: a pesquisa antropológica é sempre uma aventura dolorosa e tanto mais dói quanto mais somos frágeis pessoalmente. Alguns temas são especialmente mais dolorosos que outros e isto pode ser correlato ao gênero do pesquisador. Outros temas são acessíveis a homens ou mulheres, a depender da sociedade que estudamos. Para ficar com um exemplo pouco polêmico, é mais fácil uma antropóloga estudar uma sociedade secreta como o Sande, comum em países como a Serra Leoa e Libéria, que um antropólogo. Por outro lado, é mais fácil o último estudar o Poro, outra sociedade secreta da região. A razão me parece óbvia: o Sande é uma sociedade secreta exclusivamente feminina enquanto o Poro é uma instituição de homens. A acessibilidade a esses mundos marcados pelo segredo é obviamente diferenciada segundo o gênero.

Em resumo, tendo a pensar que a aventura africana é mais aventurosa e arriscada para as mulheres devido aos vieses de nosso olhar para o continente e, quem sabe até, aos vieses do nosso mesmo ol har para as diferenças de gênero. Mas não posso deixar de ressaltar que temas cabulosos têm sido tratados por mulheres antropólogas de modo a causar a boa inveja nos homens. E não devo passar sem nomear aquelas que me são próximas: a pesquisa da Laura [Moutinho] sobre o nacionalismo africâner e suas associações com a questão do gênero é um exemplo de como tratar exemplarmente um assunto muito difícil e sensível em termos morais, políticos e, imagino eu, até estéticos. Um outro exemplo vem do projeto da Denise [Pimenta], que li recentemente, sobre o impacto da epidemia do Ebola na Serra Leoa. Esta é uma temática dolorosa que implica grande sofrimento existencial. E eu não tenho dificuldade alguma em afirmar que a liderança da pesquisa antropológica sobre esse tópico está com as mulheres. 


\section{DOCÊNCIA, INTERNACIONALIZAÇÃO E POLÍTICA}

\section{- Atualmente, você é professor da unв e investigador associado ao Max Planck Institute for Social Anthropology. Quais são as diferenças e proximidades que você enxerga no ensino da antropologia dentro e fora do Brasil? E quais as proximidades e distanciamentos entre a antropologia feita nas mais renomadas instituições de antropologia dentro do próprio país?}

WT - Também temos pano para manga aqui. Sou professor do Departamento de Antropologia da unв há 23 anos. Ainda na unB, fui Professor Substituto nos Departamentos de Antropologia e de Música por cerca de um ano e meio. Meus vínculos com o Max Planck começaram em 2006, quando fui convidado para a primeira conferência do grupo de pesquisa Integration and Conflict along the Upper Cuinea Coast ali baseado. A conferência tinha um título aliterativo interessante. Chamava-se The Powerful Presence of the Past. Fui pela primeira vez a Halle em outubro de 2006, apresentei meu trabalho e fui convidado pela organizadora do evento e coordenadora do grupo de pesquisa, Jacqueline Knörr, para coeditar o livro resultante dos trabalhos apresentados no evento. Comentamos esses textos e escrevemos a Introdução ao volume em 2007 e desde então sou pesquisador associado ao Instituto. O livro foi publicado em 2010 pela Brill Publishers com o mesmo título da Conferência (Knörr e Trajano Filho, 2010).

Ali sempre fomos um pequeno grupo de pesquisa. Além da coordenadora do grupo, que mantém um vínculo permanente com o Max Planck, temos sido dois ou três Associados Sêniores, dois a quatro doutorandos e dois investigadores com bolsas de pós-doutorado. Atualmente, eu e Bill Murphy, da Northwestern University, somos os Associados Sêniores. Até 2014, tínhamos ainda a fabulosa companhia de Christian Hojbjerg, da Aarhus University, que nos deixou com uma saudade imensa após uma sofrida doença.

Minhas atividades no grupo de pesquisa envolvem a colaboração na organização das conferências que realizamos de dois em dois anos. Até agora foram organizadas cinco conferências, quatro delas em Halle e uma em Lisboa. Já saíram os volumes com trabalhos selecionados dentre os que foram apresentados na primeira e terceira conferências. Além do já mencionado The Powerful Presence of the Past, a coletânea The Upper Cuinea Coast in Clobal Perspective foi publicada no início de 2016 pela Bergham Books (Knörr e Kohl, 2016). O volume relativo à segunda nunca verá a forma de livro e a coletânea com os trabalhos selecionados da quarta conferência sairá no início de 2017. As quatro primeiras conferências tratavam de temas relacionados à Upper Guinea Coast, a vasta região da África Ocidental, que vai do Senegal até a Libéria, em que fazemos pesquisa. 
A quinta conferência, mais uma vez organizada por mim e por Jacqueline Knörr, aconteceu em outubro de 2014, e pela primeira vez não ficou restrita a essa área geográfica. $O$ tema geral do evento foi a crioulização das línguas e culturas e o título da conferência e do livro que será publicado em 2018 é Creolization and Pidginization in Contexts of Postcolonial Diversity. O volume conta com trabalhos de três investigadores que concluíram seus doutorados no Instituto, dos dois Associados, além de uma série interessante de textos sobre contextos de crioulização no Suriname, Cabo Verde, Ilhas Maurício e Salomões, África do Sul, Camarões, na zona swahili do leste da África e na cidade europeia de Antuérpia. Para mim, essa conferência tem um significado importante, pois, pela primeira vez, contou com a participação de duas colegas do PPCAS da unв que trabalham em sociedades crioulas africanas: Andréa de Souza Lobo e Juliana Braz Dias. Com isto, minha inserção no Max Planck de alguma forma deixou de ser uma dinâmica individual e está tomando a forma de uma rede de natureza mais institucional.

Além das conferências, temos participado, como um grupo ou individualmente, nos grandes eventos antropológicos internacionais: os encontros da African Studies Association e da Amercican Anthropological Association, nos Estados Unidos, da EASA e da ECAS, na Europa, bem como da IUAES.

A co-orientação das teses de doutorado é também uma de minhas atribuições. Nestes meus anos como Associado ao Max Planck, co-orientei duas teses: a primeira, de Anais Ménard (2015), chamada Beyond Autochthony Discourses: Sherbro Identity and the Re-Construction of Social and National Cohesion in Sierra Leone; a segunda, intitulada OfStrangers and Secrets: Continuity and Change in the Articulation of Belonging in Contemporary Liberia, de Maarten Bedert (2016). Os dois são trabalhos muito instigantes e saber que há neles um dedo do meu pensamento me deixa com um sentimento muito prazeroso.

Também realizamos como grupo de pesquisa uma oficina anual, ou em Düsseldorf, ou em algum país africano, na qual discutimos os projetos de nossos doutorandos e os nossos próprios. Essas têm sido uma excelente oportunidade para oferecer uma orientação pragmática aos nossos doutorandos, especialmente quando ocorrem em países africanos, próximos de suas áreas de pesquisa. Eles nos apresentam as dificuldades práticas que estão enfrentando no terreno e nós procuramos orientá-los sobre a melhor forma de vencê-las. Receber o aconsel hamento dos mais experientes no que toca às dificuldades de cunho prático enquanto se faz a pesquisa é uma oportunidade ímpar, que acontece, segundo é de meu conhecimento, muito raramente. Os doutorandos de nosso grupo de pesquisa têm sido privilegiados a esse respeito, e isto se reflete na qualidade elevada de suas teses.

Sobre as diferenças e proximidades no treinamento oferecido aos dou- 
torandos aqui e na Alemanha, eu primeiramente devo apontar que o Max Planck é antes de tudo uma instituição de pesquisa. As atividades de formação realizadas ali se resumem a um seminário ao qual todos os doutorandos em residência devem comparecer. São atividades regulares em que se discutem temas clássicos da disciplina. Além desse seminário, os estudantes têm a oportunidade de assistir às várias conferências organizadas pelos grupos de pesquisa dos três departamentos que compõem o Instituto. Supõe-se que parte substancial da formação dos doutorandos já tenha sido adquirida no mestrado, e aqueles que obtiveram o grau de mestre em uma área outra que não a antropologia, devem ainda seguir um ano de curso de formação geral em antropologia social, oferecido pela Universidade Martin Luther. Em todo caso, o esforço maior dos doutorandos está concentrado na pesquisa de campo, que dura pelo menos 12 meses. Em muitos casos, quando viável, eles ainda recebem um treinamento na língua em que conduzirão a sua investigação, de modo a chegar a campo com algum grau de fluência.

O fato de nosso grupo de pesquisa ter optado por não ter um elevado número de doutorandos, de poder proporcionar-lhes acesso rápido e desburocratizado a recursos financeiros e tecnológicos e de demandar deles um sentido forte de responsabilidade tem contribuído para produzir excelentes teses em um tempo relativamente curto. A maioria dos seis doutores saídos do grupo terminou seu treinamento em pouco mais de quatro anos.

Isto é diferente de minha experiência de formação nos Estados Unidos, onde a grande ênfase é posta não só na pesquisa, mas também na formação. Os doutorandos dos bons programas americanos cursam entre 18 e 20 disciplinas, além de passar por uma bateria de exames como os comprehensive e os qualifying. Além disto, demanda-se deles um longo período de campo, com o aprendizado da língua do local de pesquisa.

Eu diria que a formação no Brasil fica a meio caminho. O tempo gasto pelos nossos doutorandos em atividades de formação é certamente muito menor que o dos americanos e mais ou menos equivalente ao dos meus estudantes na Alemanha. A diferença na formação entre eles é sutil e tem a ver com o lugar ou o peso que damos aqui ao período clássico, que cobre a produção antropológica feita entre os anos 20 e 60 do século xx. Os doutorandos do Max Planck estão mais interessados em se familiarizar com o estado da arte de sua área ou tópico de pesquisa e não tanto em adquirir uma erudição que, muitas vezes, pode ser improdutiva para a pesquisa. Obviamente, cada uma dessas opções tem seus prós e seus contras. No Brasil, a pressão das agências financiadoras, poucos anos atrás, pela redução do tempo médio de formação agravou, no meu entender, a situação, produzindo um cobertor curto, que nunca é bastante para cobrir os pés e a cabeça. Assim, muitas 
vezes acabamos por diminuir a quantidade de disciplinas a serem cursadas e ainda aceitamos como normal pesquisas fragmentadas de poucos meses de duração, quase sempre uma repetição dos trabalhos de mestrado e de graduação. Felizmente, nos últimos anos, as agências têm diminuído um pouco a pressão por um tempo médio muito pequeno. Em todo caso, eu creio que essas diferenças no processo formativo são um dos atributos que contribui para dar uma feição particular e relativamente diferenciada da antropologia que fazemos aqui, lá e alhures.

Ultimamente, tenho me preocupado mais com o processo formativo dos antropólogos no Brasil. Entre nós, ainda é relativamente pequena a importância que atribuímos à pesquisa de campo longa e intensiva. Isto é correlato à formação que muitas vezes superestima o lugar da teoria, gerando uma falsa hierarquia entre teoria, produção de dados e descrição etnográfica. 0 problema com isto está associado ao fato de que em alguns programas o número de disciplinas que nossos estudantes são obrigados a cursar está diminuindo. Em vários programas brasileiros, somando mestrado e doutorado, os estudantes cursam menos de 10 disciplinas substantivas. Compare esse número com os 18 ou 20 cursos que os americanos fazem e saltará à vista o paradoxo que é superestimar o lugar da teoria.

De uma coisa estou certo, sem uma pesquisa intensiva e longa não é possível ter bons dados e sem estes não há boa teoria. Não preciso dizer que as poucas exceções, classicamente conhecidas, são isto mesmo: exceções. E mais: a teoria (toda ela, incluindo as exceções) tem vida curta, al gumas vezes muito curta.

Vocês ainda me provocam com a interessante questão sobre as diferenças e proximidades da formação nas instituições brasileiras de excelência. Não quero me estender muito sobre este tema porque não tenho dados atualizados para fazer uma reflexão adequada. Há mais de uma década, duas colegas paulistas, Guita Debert e Lilia Schwarcz, em trabalhos diferentes, se debruçaram sobre o tema da formação dos antropólogos e mostraram que as diferenças a este respeito eram relativamente pequenas nos programas consolidados. Minha intuição é de que esse quadro de relativa homogeneidade permanece, em larga medida, inalterado.

No meu entender, o que diferencia os programas é menos a carga e o conteúdo curricular e mais os atributos de natureza mais flutuante, como a composição do corpo docente, suas áreas de especialização, suas demandas idiossincráticas e a forma como respondem às agências de fomento. A respeito deste último ponto, vejo que há programas que, por assim dizer, se adiantam às demandas da Capes e cnpq e jogam o jogo da avaliação de um modo muito "profissional". Isto facilita o acesso a recursos, maximiza a 
produção intelectual em veículos de maior prestígio e qualificação, dá um ar de mais eficiência e gera uma cultura acadêmica competitiva. Outros são mais artesanais, demoram a se mobilizar para atender a novas demandas externas e, algumas vezes, resistem a elas. Isto pode ter efeitos negativos em algumas dimensões, mas, num prazo maior, pode revelar alguns aspectos positivos. Vou ficar com um único exemplo, sem dar nome aos bois. Há um programa consolidado que demorou muito em responder as pressões da Capes para redução do tempo médio de formação. Inicialmente, ele foi relativamente prejudicado por isto (não sei precisar o quanto), mas suas dissertações de mestrado, produzidas com mais vagar, ficaram comparativamente mais densas que a dos programas que adotaram muito rapidamente os padrões da Capes.

No final das contas, as diferenças pra valer mesmo estão na composição do corpo docente e nas linhas de pesquisa desenvolvidas. É isto que dá aos programas uma cara própria. Se eu fosse um jovem mestrando ou doutorando e quisesse fazer uma antropologia nas cidades e das cidades, eu não teria dúvidas em ir à usp. Se meu tesão é a etnologia indígena (nas suas duas formas mais visíveis), o Museu Nacional me pareceria o lugar mais adequado para obter minha formação. Se minha viagem é a religião, acho que o programa da Ufrgs oferece um amplo leque opções. Os estudos de gênero há muito estão em alta e tem gente boa fazendo pesquisa sobre isto em vários lugares. Porém, parece-me que o grupo associado ao Pagu, da Unicamp, ganhou uma merecida visibilidade. Se pretendo fazer pesquisa em África, Brasília é o lugar onde se concentra o maior número de gente com experiência de pesquisa naquele continente. Na realidade, o PPGAs da unв é um dos que mais se notabiliza pelas pesquisas realizadas fora do Brasil. Obviamente, não estou dizendo com tudo isto que os programas mencionados têm sua excelência restrita às tais linhas de pesquisa. Em todos eles, há investigação de altíssima qualidade em outras áreas. Tampouco quero dizer que os bons etnólogos das sociedades indígenas brasileiras só se encontrem no Museu, que só em Brasília tem gente qualificada pesquisando os mundos africanos e que não se faz boa antropologia urbana fora da usp. Posso citar dezenas de nomes de gente absolutamente reconhecida em todas essas áreas em outros programas.

- Você poderia falar das convergências, vantagens e dilemas do que temos chamado de relações "sul-sul"?

WT -O meu devaneio para o futuro da antropologia seria o seguinte: antropólogos trobriandeses interessados no mundo nilótico, de onde saem pesquisadores que querem compreender as sociedades andinas, que formam 
etnólogos interessados na cultura política escandinava, cujos cientistas sociais investigam as heterodoxias islâmicas, que produzem especialistas do social desejosos por compreender a cultura popular antropofágica no Brasil, de onde saiu este atribulado etnógrafo do mundo crioulo da costa africanatudo isto ganhando expressão num crioulo um tanto herege.

Minha utopia só seria possível se de fato levamos a sério o programa de intensificar o diálogo sul-sul. Porém, meu entendimento do que seria o sul antropológico está em desacordo com muito do que parece ser consensual na literatura. Para começar, eu não vejo com bons olhos homologias entre o norte e o sul político e o norte e o sul disciplinar ou, no caso, antropológico. A própria homologia entre esses pares nas dimensões política e geográfica já é em si tão problemática que se criou a categoria "sul global" para falar das relações políticas em nível planetário. A Austrália, sul (geográfico), não pertenceria ao sul (político). A Mongólia, norte (geográfico), não é parte do norte (político). Além disso, a dinâmica das relações entre os Estados-nações está subvertendo as consolidadas oposições centro-periferia e norte-sul. A ascensão da China à categoria de estrela de primeiríssima grandeza nas relações planetárias, a emergência e visibilidade dos Brics, a decadência de antigos impérios coloniais e centros de poder político estão tornando as distinções veiculadas por esses pares de oposição um tanto obsoletas.

De modo muito polêmico, eu sei bem, chamo de norte antropológico a produção dos centros localizados no mundo anglófono ou anglófilo. Todo o resto para mim é, de alguma maneira, sul. Assim, quando falo em diálogo sul-sul, primeiramente, refiro-me, por exemplo, às minhas trocas intelectuais com os colegas antropólogos da Cuiné-Bissau, de Cabo Verde, do Senegal, da Serra Leoa, de Mocambique e por aí vai. Porém, de modo um tanto contraintuitivo, penso também nas trocas com os colegas da África do Sul, de Portugal, Argentina, México, Espanha, Itália, Alemanha, Bélgica, Índia, Japão, Rússia, Croácia, Eslovênia, Polônia. Mais polêmico ainda, incluo nesse pacote os fluxos com os parceiros franceses.

Não tenho muito espaço para elaborar sobre isto aqui. Num simpósio da ABA coordenado pela Laura Moutinho e por Andrea de Souza Lobo, ensaiei uma reflexão sobre o potencial desses olhares/diálogos cruzados, vindos de lugares não usuais, para a constituição de um ecúmeno antropológico global que atenue, pelo menos no plano acadêmico, as desigualdades materiais e a subordinação que caracterizam as relações com o norte político. A partir de minha experiência de pesquisa em contextos africanos, penso que esse potencial estaria ligado às possibilidades de fertilização cruzada das ideias que surgem nos lugares não convencionais. Creio que isto se deve ao fato de que os olhares cruzados, a partir de lugares não convencionais, são portadores de 
inovação em três dimensões interconectadas: a mistura inusitada de tradições antropológicas consolidadas do norte, a abertura para ouvir, se deixar inspirar e ser afetado por teorias localmente produzidas (no sul) e os debates intelectuais (extra antropológicos) existentes no lugar de quem olha (com a literatura, a música, a dramaturgia e outras formas da cultura popular).

Num tom otimista para um ano que, definitivamente, não o merece, digo, com um elevado grau de certeza, que isto está acontecendo na antropologia brasileira que se voltou para o mundo além-fronteiras. Experiências como a dos Programas de Mobilidade promovidos pela Capes são exemplos do que está se passando com nossas aventuras africanas, latino-americanas e asiáticas.

As contradições e dificuldades inerentes à implementação e manutenção desse diálogo não são poucas, mas estou certo de que vale a pena enfrentá-las. Primeiramente, o diálogo sul-sul é mais caro, pois implica mais deslocamentos físicos (devido à precariedade relativa dos meios de comunicação) para lugares mais distantes, com preços mais elevados. Em segundo lugar, temos que enfrentar a variedade linguística inerente aos olhares e às falas cruzadas (que também tem consequências nos custos). O recurso a traduções (com suas irremediáveis traições) dificulta o diálogo direto entre pesquisadores do sul. A renúncia à expressão na língua materna, a adoção de uma língua franca, o que, de início, é uma desvantagem expressiva para todos os envolvidos, e o aprendizado de uma segunda ou terceira língua, sempre demorado e custoso, são obstáculos que certamente se interporão ao fluir pleno do diálogo sul-sul. Terceiro, a natureza complexa e um tanto esquizofrênica das trocas intelectuais inusitadas, devido à falta de fundamentos comuns e ao desconhecimento do que os parceiros estão fazendo. Por fim, vejo o obstáculo do localismo, em especial as estruturas de atribuição de prestígio e honra acadêmicas, que tendem a atuar de forma a minimizar os olhares cruzados e reproduzir as hierarquias (vide coisas como o Qualis).

Estou certo, contudo, de que o bônus é maior que o ônus e que vale a pena insistir em trocar figurinhas com novos parceiros. Isto produz ganhos em várias dimensões além da meramente intelectual. É também um ganho existencial e estético.

\section{- No Brasil não há uma homogeneidade temática entre os que pesquisam em África, nem em termos teóricos, nem metodológicos. Como você vê esse campo multifacetado? \\ WT -Que bom que isto é assim! Nós somos os profissionais da alteridade. So- mos nós os que primeiramente gritam: viva a diferença! Parece-me que há uma pulsão a impelir, já há algum tempo, os antropólogos brasileiros para o mundo além-fronteiras. O continente africano é apenas um dos muitos}


lugares de destino. De início, a aventura africana é uma aventura individual e o quadro geral produzido por ela é, de fato, multifacetado. Num segundo momento, a aventura ganha alguma institucionalização e a variedade temática e de inspiração teórica diminui um pouco. Acho que atualmente nos encontramos nessa fase. Ela deve ser longa o bastante para continuar dando livre fluxo às idiossincrasias das pessoas e à vontade de fazer coisas novas, mas deve ter algum grau de institucionalização que garanta uma massa crítica de trabalhos sobre temáticas ou problemas específicos, que impeça a esquizofrenia já apontada e que forneça os fundamentos para a instituição de alguma forma de honra e prestígio e algum padrão de qualidade.

\section{- Como você vê o compromisso político dos antropólogos brasileiros que pesquisam}

\section{em África?}

WT - Questão difícil e delicada, especialmente porque posta neste momento complicado que vivemos. Como eu não gosto de fugir das questões que me são postas, eu me arrisco a falar do meu compromisso político. Eu tenho um sentimento de preocupação, interesse e solidariedade com as pessoas e instituições dos lugares em que fiz pesquisa. Em alguns casos esse sentimento é mais intenso, quando, por exemplo, o Presidente Nino Vieira da Guiné-Bissau convocou tropas senegaleses e da Cuiné Conacri para se manter no poder, e a instituição que me acolheu na Guiné-Bissau, o INEP, foi severamente afetada pelas balas, foguetes ou simplesmente pelas fogueiras acesas pelos soldados senegaleses para cozinhar o seu rancho. O material usado para os fogos não era simples folhas de papel, mas documentos oriundos dos fundos do Arquivo Nacional. Perda irreparável. Isto gerou em mim um sentimento de indignação violento. Mas não enquadro minhas emoções na moldura do compromisso político. Este, eu tenho com a sociedade em que vivo. O meu compromisso político básico, realizando pesquisa em África, não é muito diferente do que eu sempre tive com relação ao meu trabalho: contribuir para a formação de pessoas conscientes de seus direitos e deveres e, com essa consciência, diminuir a desigualdade que tanto nos tem flagelado. Nem mais nem menos.

TEMA ATUAL

- Você tem se dedicado a pensar e escrever sobre a crioulização. Por favor, nos fale um pouco a respeito deste tema que lhe é tão caro. Você corrobora a ideia de que o mundo está em processo de crioulização?

WT - Começo pelo fim. Acredito sim que o mundo atual vive um processo análogo ao que os sociolinguistas chamam de crioulização. Minha colega Jacque- 
line Knörr diria que se trataria mais de um mundo em pidginização. De um jeito ou de outro, a metáfora da crioulização, conforme propôs Ulf Hannerz (1987), nos serve para falar e pensar sobre a mistura e sobre o que antes era dado como discreto e separado e agora é tomado como borrado e misturado. O que se passou, se é que algo se passou? Muita gente responde com uma palavrinha mágica: globalização. Acho que precisamos mais que isto.

Metade das polêmicas nas Ciências Sociais dizem respeito à terminologia que usamos. Quais palavras são as melhores candidatas a se tornar um conceito? Os debates a esse respeito são intermináveis, frequentemente inférteis e infelizmente inevitáveis. Sim, o mundo de hoje é muito misturado, mas, na realidade sempre o foi. Crioulização serve para chamar a atenção para isto, mas não é exatamente assim que a tenho tomado em meus trabaIhos sobre a Guiné-Bissau e Cabo Verde.

Procuro dar um sentido mais estreito ao termo e um uso mais conceitual. Eu o utilizo para me referir a um processo histórico que fez surgir uma entidade terceira de um encontro intersocietário envolvendo variadas vertentes civilizatórias. A essa entidade terceira, eu chamo de sociedade crioula. Ela não se confunde com as vertentes que participaram de seu nascimento, apesar de ter as fronteiras que a separam daquelas muito borradas ou apagadas; recruta de suas vertentes formadoras gente, práticas, valores, coisas e ideias, mas incorpora tudo isto como se dela fizessem parte. O problema é que nem todo encontro intersocietário produz uma sociedade crioula. Devemos então indagar sobre as condições de emergência da crioulização. Daí surge uma série de questões interessantes: o que diferencia a crioulização de uma simples mistura e a torna um conceito mais rico que outros similares, como hibridização e mestiçagem? Uma sociedade crioula se caracteriza por algum atributo estrutural ou ela só é assim caracterizada por sua história? Sendo um processo, como a crioulização termina?

Usada desse modo, a ideia de crioulização me tem sido útil para alcançar algumas generalizações. Além disto, tem se mostrado muito produtiva para formular hipóteses sobre a dinâmica das sociedades crioulas em cada momento de suas histórias, de modo semelhante ao que os socioliguistas fazem no estudo das línguas crioulas.

\section{LEITURAS}

\section{- Os estudos em África estão crescendo no Brasil, o que você diria para um jovem antropólogo que tem interesse em pesquisar em países do continente?}

WT - Vou ser curto e grosso sobre isto. Primeiro, que ela ou ele jogue parte substancial de suas energias numa pesquisa de campo cuidadosa, longa e inten- 
siva. Que aprenda a língua local e dialogue intensamente com os seus pares locais. Que não vá para África com um olhar colonizado, nem volte querendo colonizar. Explico-me. Que evite o mais possível toda forma de epigonismo e babaovismo para com os olhares hegemônicos, frequentemente disfarçados de libertários ou contra-hegemônicos (a isto chamo ol har colonizado). Mas, se sucedeu de nossa amiga ou amigo ter ido com esse espírito, que se liberte durante a experiência africana com o diálogo com os pares locais, e não retorne querendo fundar igrejas e colonizar mentes. Infelizmente tenho visto alguns casos assim. Ainda bem que são poucos. Segundo, que tenha a boa ambição e a energia para estabelecer diálogos complicados, quase esquizofrênicos: com os colegas brasileiros, que pouco sabem sobre África; com os colegas africanos em sua frequente precariedade institucional; com os parceiros dos centros hegemônicos (os de algumas instituições anglófonas ou anglófilas); e, sobretudo, com os estudiosos de África oriundos de lugares (e portadores de olhares) inusitados: do Japão, do México, da Índia, Rússia, China, Argentina, e toda uma plêiade de instituições europeias e latino-americanas que dificilmente poderíamos chamar de centrais no mundo de hoje. Em lugares como Portugal, Espanha, Alemanha, Eslovênia, Bélgica, Croácia, Itália e provocativamente incluiria até mesmo a França, tem gente fazendo uma boa antropologia baseados em instituições que dificilmente poderíamos caracterizar hoje como centros do pensamento antropológico. Terceiro, que vá procurando ter uma boa vida em campo, que seja uma experiência prazerosa. A receita para isto é relativamente simples: um pouco de bom senso, no sentido de ter ciência dos seus limites, ser minimamente safo para escapar, com sutileza, das situações difíceis (na Guiné isto é chamado de dubriagem e nos país francófonos as pessoas se referem a isto como se débrouiller) e uma vocação para a sociabilidade. Ser egoísta, individualista e fechado em si mesmo não ajuda em nada.

\section{-O que você acha que tem sido feito de interessante, atualmente na antropologia sobre África? Qual a bibliografia atual tem lhe despertado interesse?}

WT - Poucos anos atrás, num artigo em comemoração aos 40 anos do Instituto de Ciências Sociais da Universidade de Brasília (Trajano Filho, 2011), eu dizia que andava um tanto desencantado com muito do que se chama antropologia. Na verdade, tenho lido os textos antropológicos sem muito encantamento: dos sentidos e da razão. Acho que a linguagem ficou muito cheia de jargão, a lógica teórica cheira mais a marketing, as descrições são confusas e as preocupações, muitas vezes, distantes das minhas. Isto se aplica à antropologia como um todo, mas o meu viés formativo se desencanta mais com aquelas peças que não têm sociedade como hóspede, se satisfazendo com 
uma ideia frouxa de cultura e deixando correr à solta aquilo que Umberto Eco uma vez chamou de superinterpretativismo. A antropologia feita sobre os mundos africanos não está livre disto e, portanto, meu desalento também se refere a ela.

Penso, porém, que, se uma coisa deu certo na vida da disciplina foi o seu casamento com a história, em especial com uma história de inspiração etnográfica, que conjuga material de arquivo e as memórias vivas das pessoas. Tenho lido muita coisa boa feita por gente de filiação disciplinar variada sobre o mundo das cidades africanas nos períodos colonial e pós-colonial. Os tópicos tratados são muito variados, mas em geral trata-se da miuçaIha temática cara aos antropólogos, os temas pequenos, frequentemente subestimados em sua produtividade por sociólogos, cientistas políticos e economistas. Refiro-me aos esportes, aos gêneros narrativos que comporiam uma literatura popular, à moda, música, formas dramáticas, aquilo que poderíamos chamar de artes visuais (pintura e escultura), práticas de sociabilidade variadas como a dança o consumo de álcool, a prostituição e hábitos de consumo associado ao tratamento do corpo, entre outros. Para cada um desses temas eu posso citar alguns trabalhos muito interessantes, que não se satisfazem em ficar no pequeno, esboçando conclusões muito interessantes e diferentes das abordagens ortodoxas e superinstitucionalizadas sobre coisas como o colonialismo, a cultura política das sociedades coloniais e pós-coloniais e os fluxos de coisas, gente e ideias entre essas sociedades e aquilo que (muito a contragosto) chamamos de centro. Enquadro todos esses temas na moldura da cultura popular.

\section{FUTUROS PROJETOS}

\section{- Bem, após conseguir um dos graus mais altos da vida acadêmica, anterior apenas ao de Professor Emérito, quais são os próximos projetos?}

WT - Vou ser econômico sobre isto. Estou com 62 anos e tudo que espero ainda fazer é encontrar alguma consistência em tudo que fiz. Para isto meu projeto de agora em diante é mostrar a confluência lógica e necessária entre crioulização e cultura popular (que são as áreas que trabalhei durante toda a minha carreira antropológica). A última tende a ser efervescente em contextos marcados pela primeira. A única novidade que imagino poder aportar é oferecer uma nova concepção do que seja cultura popular. Tenho evitado tratá-la como um conjunto específico de formas expressivas (música, arte, danças...), como de modo geral tem sido feito. Termino telegraficamente, quem sabe gerando alguma expectativa por causa da forma enigmática com que vou enquadrar a questão. Para mim, cultura popular é uma dimensão da 
vida social em que a cultura se desmente, lutando contra si mesma por meio de eternas incriminações acerca de sua verdade e de sua pretensa natureza não imitativa.

Denise Pimenta é mestre e doutoranda pelo Programa de Pós-Craduação em Antropologia Social da usp. Realiza trabalho de campo em Serra Leoa (Oeste Africano), desenvolvendo a pesquisa intitulada: "O gênero da sobrevivência: por detrás do Ebola", que analisa a relação entre a epidemia de Ebola de 2014-2016 e as questões de gênero.

Laura Moutinho é Doutora em Antropologia Cultural pela UfR] e Professora do Departamento de Antropologia da USP, sendo bolsista produtividade do CNPq desde 2008. Foi pesquisadora visitante no African Cender Institut, da University of Cape Town (UCT) na África do Sul e Visiting Professor of Public and International Affairs na Universidade de Princeton, Estados Unidos.

Pedro Lopes é mestre e doutorando em Antropologia Social pela usp. Participou da pesquisa internacional "Relations among 'race', sexuality and gender in different local and national contexts", coordenada por Laura Moutinho, dedicando-se à investigação sobre a Cidade do Cabo, na África do Sul. Atualmente, é professor do curso de Arquitetura e Urbanismo da Escola da Cidade.

\section{REFERÊNCIAS BIBLIOGRÁFICAS}

BÉDART, Maarten

2016 Of Strangers and Secrets: Continuity and Change in the Articulation of Belonging in Contemporary Liberia. Halle, tese, Martin-Luther Universität.

DIAS, Juliana Braz; THOMAZ, Omar Ribeiro; TRAJANO FILHO, Wilson; e SILVA, Kelly Cristiane

2008 "Brazilian Anthropologists in Africa: Remarks on Theory, Politics and Fieldwork Overseas". Vibrant, v. 5: 277-303.

HANNERZ, UIf

1987 "The World in Creolization". Africa, 57(4): 546-559.

KNÖRR, Jacqueline e TRAJANO FILHO, Wilson (orgs.)

2010 The Powerful Presence of the Past: Integration and conflict along the Upper Cuinea Coast. Leiden, Brill. 
KNÖRR, Jacqueline e KOHL, Christoph (orgs.)

2016 The Upper Cuinea Coast in Clobal Perspective. Nova York, Berghahn Books.

MÉNARD, Anais

2015 Beyond Autochthony Discourses: Sherbro Identity and the (Re-)Construction of Social and National Cohesion in Sierra Leone. Halle, tese, Martin-Luther Universität.

TRAJANO FILHO, Wilson

1984 Músicos e música no meio da travessia. Brasília, dissertação, Universidade de Brasília.

1993 "Rumores: uma narrativa da nação". Série Antropologia, Brasília, p. 1-54.

2011 "Dilemas, projetos e questões: reflexões quase musicais de um antropólogo convertido". In RIBEIRO, G. L.; FERNANDES, A. M.; MARTINS, C. B.; e TRAJANO FILHO, W. (orgs.), As Ciências Sociais no mundo contemporâneo. Brasília, Letras Livres/Editora unB.

TRAJANO FILHO, Wilson e RIBEIRO, Gustavo Lins (orgs.)

2004 O Campo da Antropologia no Brasil. Rio de Janeiro, Contra Capa. 